\title{
Measurements of mass balance in dense snow avalanche events
}

\author{
Betty Sovilla, ${ }^{1}$ Francesco Sommavilla, ${ }^{2}$ Alvise Tomasellit ${ }^{2}$ \\ ${ }^{1}$ Swiss Federal Institute for Snow and Avalanche Research, CH-7260 Davos Dorf, Switzerland \\ ${ }^{2}$ Venetian Region - Avalanche Centre of Arabba, I-32020 Arabba (BL), Italy
}

\begin{abstract}
Since 1993 the Avalanche Centre of Arabba has managed a test site to determine avalanche-dynamics parameters (Sommavilla and others, 1997; Sommavilla and Sovilla, 1998). The system is located on an avalanche track which is representative for the Dolomites, northern Italy. It monitors avalanche pressures, speed, flow height and variations of the avalanche shape and extent. In winter 1997/98, together with the standard measurements, a series of new field measurements and observations of the snow cover on the avalanche path were conducted for the first time in order to accurately determine the avalanche mass balance. The information collected is typical for dense flow avalanches which have small dimension and develop mainly along a channelled path. In winter 1997/ 98 , four events were studied. For each event, in several sections from the starting zone to the deposition zone, manual measurements were carried out in order to investigate mass entrainment and deposition processes. The mass evolution of the avalanche has been determined. It is shown that the avalanche mass increases by up to $720 \%$ with respect to the initial release mass. This entrainment process is related to the speed reached by the avalanche front. In addition, it has been determined that during the acceleration phase of the avalanche front the underlying snow cover is mostly eroded and there is no deposition of snow. In the deceleration phase, by contrast, erosion decreases progressively, reaching the value zero, while deposition becomes progressively larger. These results underscore the importance of the mass balance as a fundamental component in avalanche-dynamics research.
\end{abstract}

\section{INTRODUGTION}

In recent decades, avalanche research centres (Kotlyakov and others, 1977; McClung and Schaerer, 1985; Kawada and others, 1989; Nishimura and others, 1993; Marco, 1995; Dent and others, 1998; Issler, 1999) have studied the behaviour of real avalanches with the aim of obtaining a detailed understanding of snow avalanches. The main focus has been to determine (1) avalanche impact pressures (studying the interaction between avalanches and different types of structures); (2) tangential and normal forces at the base of flow; (3) frontal and internal velocities; (4) flow density and depth profiles; and (5) friction coefficients indispensable for the application of the models. With regard to the mass balance, the only information available is the avalanche mass in the starting zone and in the deposition zone. There is no information related to the evolution of the mass along the track.

In the avalanche-modelling sector the situation is similar. The dense avalanche flow is simulated using two main modelling approaches (Barbolini, 1996; Harbitz, 1998; Harbitz and others, 1998): the "centre-of-mass" approach where the avalanche flow is described following its centre of mass along a predefined trajectory, and the continuous approach where the avalanche flow is described using fluidmechanical principles. The theories derived from these principles often include terms for entrainment and deposition, but few of them implement these terms in the numerical solution, and in these cases the formulation of the entrainment and deposition is subjective and without experimental basis.
An exception is represented by studies carried out by the Moscow State University researchers. Grigorian and Ostroumov (in press) introduced in their work the entrainment along the path. They assumed an entrainment rate proportional to the speed of the frontal rupture propagation produced by the avalanche in the snow cover, and proportional to the ratio between the density of the avalanche and the density of the snow cover. Alternatively, they proposed a relation between the erosion rate and the shear stress exerted by the avalanche on the snow layers. Eglit (1983), in her coupled dense-flow-powder-snow model, conjectures an entrainment rate proportional to the avalanche front speed. In each case, however, references reporting experimental analyses concerning this problem are lacking.

\section{MASS BALANCE}

Most avalanche numerical models assume that the mass of the avalanche is constant along the track, using the hypothesis that the snow mass that starts from the release area is the same mass that arrives in the deposition zone. In reality, observations of the avalanche path immediately after the passage of the avalanche show that the snow cover is changed. Part of the snow cover is eroded, sometimes down to the ground, and at the same time local or continuous deposits are distributed along the path. These observations have prompted analysis of the mass variations along the avalanche path in order to determine the correlation between the mass evolution and the initial mass. 
In order to collect the necessary information, field measurements have been carried out. On a specific avalanche path, different events have been studied, analyzing several sections from the starting zone to the deposition zone, with the aim of determining erosion and deposition quantities. In each section, the avalanche mass has been calculated, adding to the initial mass the quantity of snow eroded by the avalanche and subtracting the quantity of snow deposited by the avalanche. This analysis does not permit verification of the physical behaviour of the entrainment and deposition processes. Therefore, a series of dynamical pressure measurements against different kinds of surfaces, speeds and height of flow are necessary. The additional information improves the interpretation of the measured data.

\section{THE TRAGK AND THE AVALANCHE TYPOLOGY}

The analyzed zone is situated in an internal area of the Dolomites, northern Italy. The site is located on the western side of the mountain Pizzac to the south of the village of Arabba in the commune of Livinallongo del Col di Lana (BL). Typical events at this site are wet dense flow avalanches at the end of winter, and dry or moist dense flow avalanches in mid-winter. The four events analyzed during winter 1997/ 98 are examples of these kinds of avalanche. Given the maximum possible extension, the avalanches start at $2200 \mathrm{~m}$ a.s.l. and stop at $1745 \mathrm{~m}$ a.s.l., flowing down a slope with an average angle of $31^{\circ}$. The release zone is characterized by an average slope of about $40^{\circ}$ and a lack of any significant accumulation of drifted snow. The slope is oriented to the west, and exposure to the sun is limited to $2-3 \mathrm{~h}$ during the period December-January, reaching 5-6h at the end of winter. The maximum possible length of the starting zone is $170 \mathrm{~m}$; the maximum area of the release zone is $5750 \mathrm{~m}^{2}$, with a corresponding maximum volume of approximately $3450 \mathrm{~m}^{3}$.

The track of the avalanche has a gully-shaped crosssection characterized by some variations of substratum, and the gradient is $31-36^{\circ}$. Below $1832 \mathrm{~m}$ a.s.l. the gradient decreases to $25^{\circ}$, and at this point the avalanches usually stop or deposit much of the transported material. At $1783 \mathrm{~m}$ a.s.l., the end of the channelled part of the track, the accumulation develops on an open slope having an average gradient of $23^{\circ}$. A creek stops the avalanche at $1745 \mathrm{~m}$ a.s.l.

\section{METHODOLOGY OF DATA COLLEGTION AND ELABORATION}

\section{Characteristics of the original snow cover}

Although we intended to survey the avalanche area before each event, unexpected changes of weather and sudden avalanche release prevented this. The information on the original snow cover was collected in areas adjacent to the starting and flowing zones where the snow was not influenced by the passage of the avalanche and where local variations of the snow cover due to topographic factors (hole or small difference in slope) or meteorological influence (wind transport) did not occur.

The information collected is used to determine the snowcover stratigraphy along the avalanche path. A density value is given to each snow layer. On average, the snow cover is rather homogeneous along the path and there is no significant accumulation of drifted snow. The only exception is the first part of the flowing zone, where a deep gully section can accumulate snow and consequently has a higher snow cover.

The snow cover has rather homogeneous characteristics along long pieces of track, but the local stratigraphies could show small differences in the layers (height, density). In order to minimise data-collection errors due to local irregularity of the ground, the profile of the snow cover used for the massbalance calculations is the average of the collected profiles.

\section{Release zone}

The area of the release zone is determined by plotting the observed border of the release zone on a high-resolution topographic survey (map 1:500, contour line resolution $1 \mathrm{~m}$ ). Inside the release area six scaled stakes, anchored to the ground, were set in order to determine the snow height before and after the avalanche event. These stakes, 3.6 and $1.5 \mathrm{~m}$ high, respectively, have a yellow-black scale which permits the height of the snow to be determined from a safe distance with a precision of $5-10 \mathrm{~cm}$. Under safe conditions it is possible to access the starting zone, and in this case measurements are obtained by manual surveying of the undisturbed snow cover and the area of release. (Access to the release zone was possible for three of the events, so the data of interest were collected manually.) The initial avalanche volume is obtained by multiplying the average value of the snow height and the area of the release zone. Snow-pit studies with ram penetration measurements made in an area not influenced by the avalanche passage were used to define the structure of the snowpack. A value of density is given to each layer. After determination of the layers involved in the avalanche, the initial avalanche mass can be calculated.

\section{Flowing and deposition zones}

The track above the deposition zone was surveyed manually. For this purpose several representative points were chosen along the avalanche track, and for each point, along transects perpendicular to the flow direction, the following information was collected: flow width, width of the deposit (if present) and total height of the snowpack at numerous points along the transect. The distance between two consecutive investigation points was also measured.

This information is used to define the transversal profile of the sections after the passage of the avalanche. At representative sections a simplified snow profile allows determination of the deposited layers, the underlying snow cover and the eventual presence of layers formed after the event from newsnow precipitation or wind-transported snow. Density was measured at each layer. The erosion is determined by comparing these data and the data of the undisturbed snow cover.

The snowpack consists of a series of layers having dissimilar features (density, height) that after the passage of the avalanche are partially or completely eroded, moderately compacted and sometimes covered with the avalanche deposit. When the layers remaining on the ground are recognized and the new values of density and height are collected, it is easy to calculate the erosion using a simple proportion between the initial and the new condition of the snow. As an example we consider a layer having the initial characteristics density $\rho_{1}$ and height $h_{1}$, which after the passage of the avalanche is situated on the surface or immediately below the deposit with the new features density $\rho_{1 \mathrm{~b}}$ and height $h_{1 \mathrm{~b}}$ If the relation $\rho_{1} h_{1}=\rho_{1 \mathrm{~b}} h_{1 \mathrm{~b}}$ is fulfilled, then there has been no entrainment 
and the layer has only been compressed. If it is not fulfilled, then the avalanche has eroded an amount of snow equal to $h_{\mathrm{eros}}=\left(\rho_{1} h_{1} / \rho_{1 \mathrm{~b}}-h_{1 \mathrm{~b}}\right)$ having density $\rho_{1 \mathrm{~b}}$.

For each of the examined sections this procedure is used to determine the erosion and deposition areas. The average of the erosion areas of two consecutive sections multiplied by the distance between the sections provides the entrainment volume in the examined sector. A similar procedure is used to determine the deposition volume. It is possible to calculate the mass, since the density of each section is known.

\section{ANALYSIS OF EVENTS}

During the winter, avalanche events are frequent at the Pizzac site. Four events occurred during winter 1997/98, on 5 and 21 December and on 14 and 28 April.

On account of the topographic characteristics of the site (strongly gully-shaped), snow is deposited on previous events. This complicates the field measurements because the stratigraphy is influenced by previous deposits distributed along the path or by previous erosions which have already collected parts of the original snow cover. Therefore an avalanche stratigraphy requires a special interpretation, allowing determination of snow layers not eroded by the avalanche, the avalanche deposits and the layer formed after the passage of the avalanche (fresh snow, drifted snow). In most cases, the layers can be distinguished by their hardness, density, granulation, colour and impurity. If the avalanche history of the site is well known, the correct origin can be attributed to each layer.

Given the various situations which can be met during the survey, the quantity of the collected data and the modality of the data elaboration could change every time in function of the needs. Consequently, for the 5 December avalanche, the first of the season, the data were collected at 21 sections uniformly distributed along the flowing zone, and for the 21 December avalanche, which took place a few days later, 39 sections were analyzed.

\section{Mass balance of 5 December 1997 event}

The 5 December avalanche was the first event of the season on the Pizzac site. After a snowfall of about $30 \mathrm{~cm}$ on a snowpack of about $60 \mathrm{~cm}$, an attempt was made to release the avalanche. The explosion triggered a small dry-slab avalanche which affected a layer of about $25 \mathrm{~cm}$ with an aerial extension of about $1000 \mathrm{~m}^{2}$ and a corresponding volume of about $250 \mathrm{~m}^{3}$. It is difficult to determine the release zone because if the fracture line is well defined, the stauchwall (lower limit of the release zone) of the slab is frequently indistinguishable. For simplicity we will consider the stauchwall position at the same place as the first examined section.

The average density of the layer involved in the avalanche was about $135 \mathrm{~kg} \mathrm{~m}^{-3}$, corresponding to an initial avalanche mass of $33700 \mathrm{~kg}$. The avalanche collected snow along the path, eroding very deep layers. The sum of the mass eroded by the avalanche reached a value of $303000 \mathrm{~kg}$. Immediately downstream of the starting zone, the avalanche began to deposit material with a medium density of $280 \mathrm{~kg} \mathrm{~m}^{-3}$. The maximum value of the avalanche mass along the path was about $61600 \mathrm{~kg}$, equivalent to 1.8 times the initial mass. The avalanche moved downstream with an average front speed of

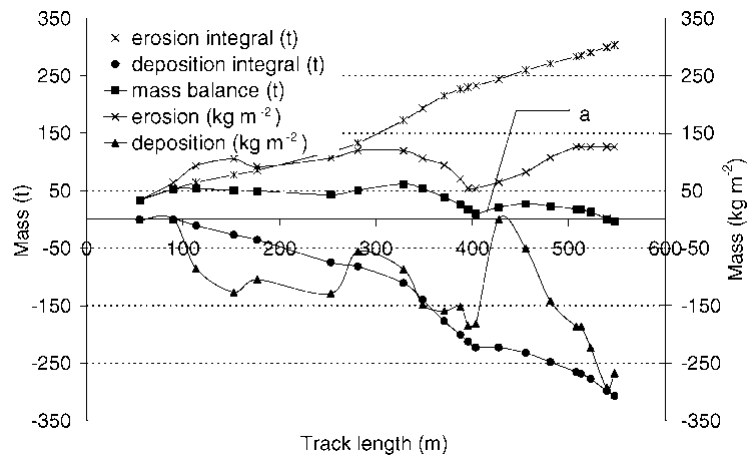

Fig. 1. Mass balance, 5 December 1997 event.

$11 \mathrm{~m} \mathrm{~s}^{-1}$, covering a total distance of $547 \mathrm{~m}$ (from the slab crown to the final deposit). The speed was characterized by many fluctuations because of the high friction along the undisturbed surface and was still influenced by the morphology of the ground. These fluctuations almost stopped the avalanche after approximately two-thirds of the total path length (point a in Fig. 1), but then, with a sudden change of slope, the avalanche recovered mass and speed.

Figure 1 shows the integral of the entrainment (erosion/ positive) and of the deposition (negative) along the avalanche trajectory. The sum of the integrals allows the evolution of the avalanche mass along the track (mass balance) to be determined. The figure also shows the evolution of the erosion and deposition values for unit of surface $\left(\mathrm{kg} \mathrm{m}^{-2}\right)$. Each point represents a section. The origin of the $x$-axis marks coincides with the slab crown. The first data point on the integral erosion curve is the released mass.

\section{Mass balance of 21 December 1997 event}

The second avalanche, on 21 December, was partially coincident with the trajectory of the first avalanche. The larger width of this event eroded undisturbed areas that consequently still had a high snow cover. In some areas immediately downstream of the starting zone, an average height of about $1.40 \mathrm{~m}$ was recorded. This high value is also explained by the fact that the area is strongly gully-shaped and that a steep wall delimiting one side of the gully tends to discharge snow inside the site.

The avalanche was triggered artificially after a snowfall of about $40 \mathrm{~cm}$. The explosion provoked a dry-slab avalanche. The total volume of the released mass was $595 \mathrm{~m}^{3}$, of which $490 \mathrm{~m}^{3}$ came from the main basin and $105 \mathrm{~m}^{3}$ from a lateral branch. The initial mass reached a value of $84400 \mathrm{~kg}$. The avalanche collected snow along the flowing

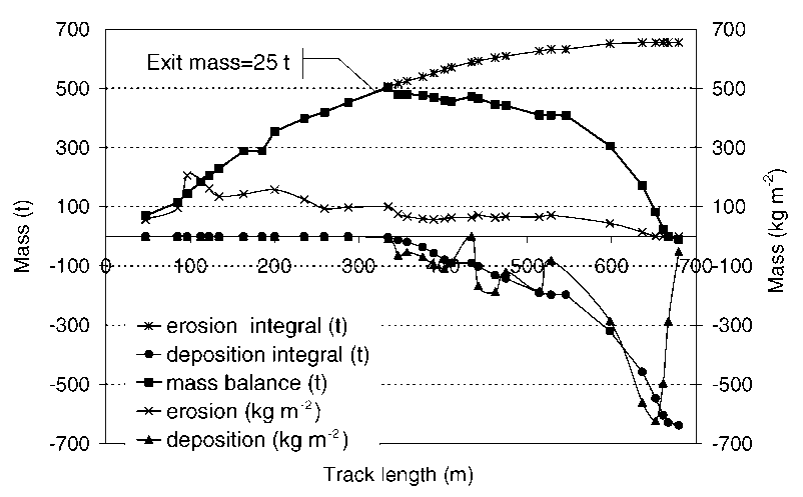

Fig. 2. Mass balance, 21 December 1997 event. 


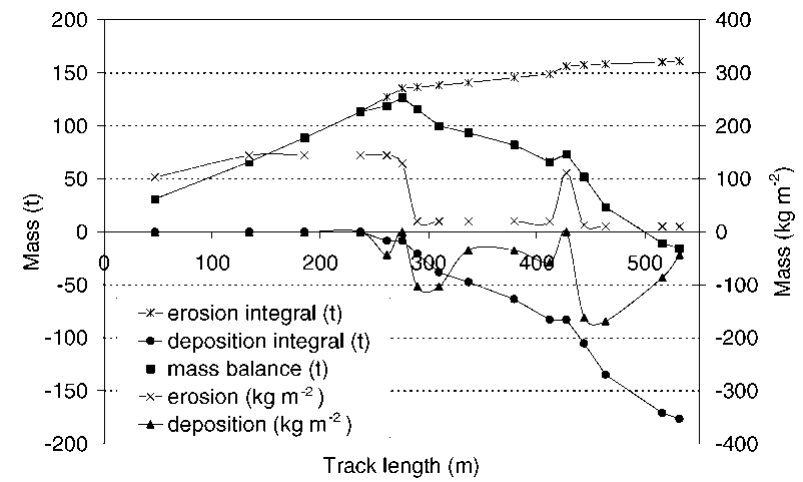

Fig. 3. Mass balance, 14 April 1998 event.

zone, also affecting deeper layers. The total mass eroded by the avalanche was $654000 \mathrm{~kg}$. The avalanche covered a total length of $680 \mathrm{~m}$; the deposit began after $300 \mathrm{~m}$ of trail. The density of the deposited snow was $270-430 \mathrm{~kg} \mathrm{~m}^{-3}$. The avalanche reached a maximum mass of $505850 \mathrm{~kg}$, which is 7.2 times the initial mass, and had an average front speed of $17.9 \mathrm{~m} \mathrm{~s}^{-1}$. Figure 2 shows the mass-balance analysis of this event. At about half-track, a small avalanche part was deflected by a defence structure protecting a cable-way pylon close to the flowing zone. This mass loss is included in the avalanche mass balance.

\section{Mass balance of 14 April 1998 event}

After a 3 month pause, a storm front deposited $80 \mathrm{~cm}$ of snow in 3 days. The high temperatures typical during spring had already caused the old snowpack to melt, except for a very thin layer of metamorphosed snow at the previous avalanche deposits less exposed to sun effects. On 14 April a moist-snow avalanche slab about $45 \mathrm{~cm}$ thick was artificially triggered. The total surface of the slab was $600 \mathrm{~m}^{2}$, corresponding to a volume of $270 \mathrm{~m}^{3}$ and a mass of $30900 \mathrm{~kg}$. The avalanche collected snow along the track, reaching the ice layer or the ground in the first part of the track, and the erosion progressively decreased towards the bottom of the slope. The mass eroded reached a value of $160900 \mathrm{~kg}$. The avalanche covered a total length of $530 \mathrm{~m}$; deposition began after $250 \mathrm{~m}$ of track. The density of the deposited snow was $290-345 \mathrm{~kg} \mathrm{~m}^{-3}$. The avalanche reached a maximum mass of $126800 \mathrm{~kg}$, corresponding to 4.1 times the initial mass, and had an average front speed of $12.3 \mathrm{~m} \mathrm{~s}^{-1}$. Figure 3 shows the mass-balance analysis of this event.

\section{Mass balance of 28 April 1998 event}

The new precipitation of 27 and 28 April produced about $75 \mathrm{~cm}$ of snow. During the 28 April precipitation, at $1240 \mathrm{~h}$, a natural release of a loose wet-snow avalanche resulted in a snowpack thickness of about $45 \mathrm{~cm}$ (all the fresh snow on the ground at the moment of the release). In this case it was not possible to access the starting zone, so data on the first part of the event are missing from the first part of the flowing zone. Observation of the phenomenon from a moderate distance showed the presence of a ground avalanche which followed more or less the same trajectory as the 14 April avalanche occupying the same width.

The missing areas and volumes were therefore estimated on the basis of the previous avalanche, choosing the same release area and a width of the flowing zone equal to the average value of the corresponding widths of the 14 April

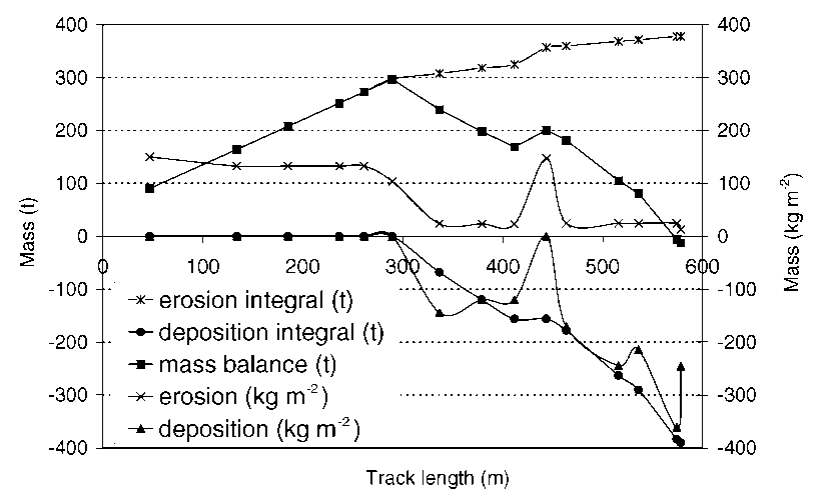

Fig. 4. Mass balance, 28 April 1998 event.

event. Densities in the first part of the track were assumed equal to those in the second part. Assuming a density of $500 \mathrm{~kg} \mathrm{~m}^{-3}$, the release mass reached a value of $90000 \mathrm{~kg}$. The avalanche collected snow along the track, reaching the ground in the first part of the track, and the erosion progressively decreased towards the bottom of the slope. The integral of the erosion reached a value of $378000 \mathrm{~kg}$. The avalanche covered a total length of $580 \mathrm{~m}$; deposition began after $310 \mathrm{~m}$. The density of the deposited snow was $500-560 \mathrm{~kg} \mathrm{~m}^{-3}$. The avalanche reached a maximum mass of $296700 \mathrm{~kg}$, corresponding to 3.3 times the initial mass, and had an average front speed of $7.6 \mathrm{~m} \mathrm{~s}^{-1}$. Figure 4 shows the mass-balance analysis of this event.

\section{ERROR ANALYSIS}

The main difficulty of field measurement is that the snow cover is not homogeneous and its characteristics change from position to position. For example, a profile is only representative of a precise point situation, and if we try to analyze another profile only a few meters distant from the first we will find something similar but not equal.

A second problem is that the precision of the measurement (e.g. $1 \mathrm{~m}$ depth with a precision of $0.5 \mathrm{~cm}$ ) is negligible in comparison to the problem of defining the point we want to measure. For example, the line of separation between two layers is not always well defined and its depth can be greater than the instrument precision.

Considering these problems, we assume that the error has two main causes: (1) the difficulty in distinguishing and exactly defining the boundary of the layers, deposits, etc.; and (2) the assumption that local information is representative for the entire snow cover. In addition, we must consider the error in the determination of the density of each layer or deposit.

These kinds of error are very difficult to define with absolute precision. In order to show the possible magnitude of the errors, we will introduce different scenarios assuming a realistic measurement error and calculating the influence of this error on the global mass-balance determination. The characteristics of the original snow cover, the released mass and the flowing and deposition zone masses have been calculated using three different methods. An error analysis is made for each case.

\section{Original snow cover}

In order to minimize data-collection errors due to the local irregularity of the ground, the snow-cover profile used for 
the mass-balance calculations is the average of the measured profiles. Erosion masses have been calculated on the basis of this profile. In particular, the depth and the density of the layers have been determined as an average of the corresponding measurements in different profiles. The number of measurements differs from event to event; in general, for each analyzed cross-section along the path there are at least five measurements (in some cases up to 20) of the depth of the undisturbed snow cover, and a stratigraphy is available for up to five sections. For each stratigraphy, density measurements were also collected.

The snow cover maintains similar characteristics over long sections of track, and a profile was calculated for each of these sections. Looking at the average depth and at the deviation of the data points from this value, we assume that the error associated with this measurement is about $5 \%$ $(5 \mathrm{~cm}$ over $1 \mathrm{~m})$. An average value of density was calculated for each layer. Averages were calculated using a minimum of 10 data points. Looking at the average of the density data and at the deviation of the data points from this value, we assume that the error associated with this measurement is about $10 \%$.

\section{Release zone}

In the high-resolution topographical survey some reference points have been inserted in order to facilitate delimitation of the boundary of the release zone. The boundaries of the release area are easy to define since they are located at sudden changes of slope or along the border of the neighbouring forest. The determination of the avalanche stauchwall is more difficult since it is frequently erased by the passage of the slab. To avoid errors caused by the determination of the position of this border, we have assumed that it is located in the lowest possible position where the avalanche starts to be channelized and where there are evident signs of flow. In this way the area is eventually over-calculated (by the order of up to $15 \%$ ). This means that if we calculate the increase of mass of the avalanche as the ratio between maximum mass and released mass, because of this error, the increase in mass can only become greater.

In addition, we have to consider the error due to the determination of the density and of the depth of the snow layers involved in the release. Because the analysis of the measurement is similar to that used to determine the profile of the original snow cover, we assume also the same magnitude of errors.

\section{Flowing and deposition zone}

In a cross-section the snow-cover depth is measured every $50 \mathrm{~cm}$. A stratigraphy measurement allows the determination of the depths corresponding to the deposit and to the original snow cover. These data are used to calculate the deposition area. The stratigraphy measurements allow observation of the erosion (which layers have been eroded and which are still on the ground). The erosion was determined using the original averaged profile of the snow cover.

In the following we assume a realistic measurement error and we calculate the influence of this error on the calculation of the area. For an average cross-section with the snow deposit 70-190 cm deep and about $7 \mathrm{~m}$ wide, assuming an error of $10 \mathrm{~cm}$ for each measurement, the variation of the global area is about $8 \%$; an error of $5 \mathrm{~cm}$ produces a difference in the area of about $5 \%$. Given the fact that there is an absolute error of

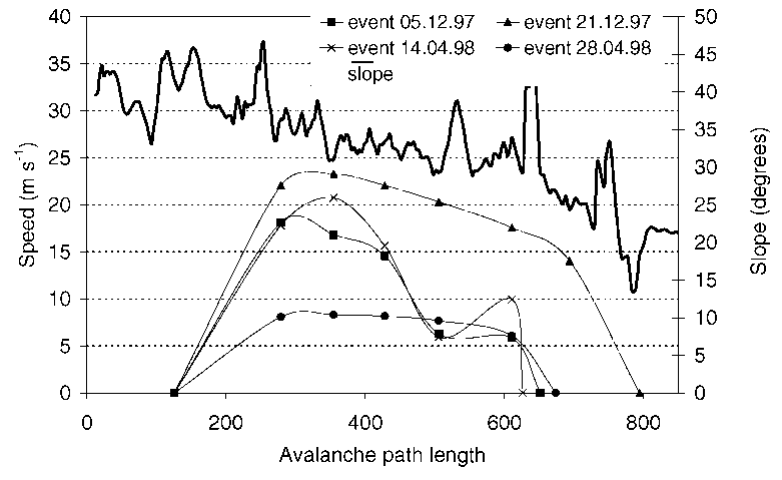

Fig. 5. Speed of the considered events.

$10 \mathrm{~cm}$ over these values of depth, and that it is difficult to repeat this error constantly for the entire measurement, we assume that the second case is the more realistic.

The average deposition area of two consecutive sections multiplied by the distance between the sections gives the volume of the deposit. The volume multiplied by the density gives the mass. The density is calculated as an average of the data collected in the two consecutive sections. The density of the deposit is generally in the order of $300 \mathrm{~kg} \mathrm{~m}^{-3}$; an error of $10 \%$ in this measurement means a difference of $30 \mathrm{~kg} \mathrm{~m}^{-3}$. The instruments have a precision of $10 \mathrm{~kg} \mathrm{~m}^{-3}(3 \%)$. Since we do not use local information, but only the average of many data (10-20 data points), the final error can only decrease. Thus, the error in the definition of local area or density does not influence the results of this work. What can strongly influence the result is the fact that we measure area or density in specific positions and that we extend these data over the entire snow cover. In effect, the section and the profile have been carefully chosen to represent the variation along the avalanche track, and in each case it has been observed that variations are not very important. Control over this kind of error is given by the fact that, when the avalanche stops, the sum of eroded and deposited snow must be zero, indicating that the avalanche has deposited all the eroded snow.

For the examined events the calculated avalanche mass when it comes to rest is not zero, but the difference is small (see Figs 1-4). The average error is $11.8 \%$ of the release mass and only $3.9 \%$ of the maximum mass obtained by the avalanche along the path. An exception is the 14 April event, for which the percentage increased to $50 \%$ and $12.3 \%$, respectively. Since erosion and deposition masses have been calculated with different methods, the respective errors are mutually independent. The fact that the final error is not so large means that in effect the local data represent the entire snow cover well.

In conclusion, it is difficult to quantify a precise error, but it is possible to state that the entity of the error does not influence the conclusions of this work.

\section{SPEED ANALYSIS}

There are six points, uniformly distributed along the track, where the time of the avalanche passage can be recorded (Sommavilla and Sovilla, 1998). These points are positioned at known distances, and when release time has been recorded it is possible to determine the position of the avalanche along the track in function of the time. This 


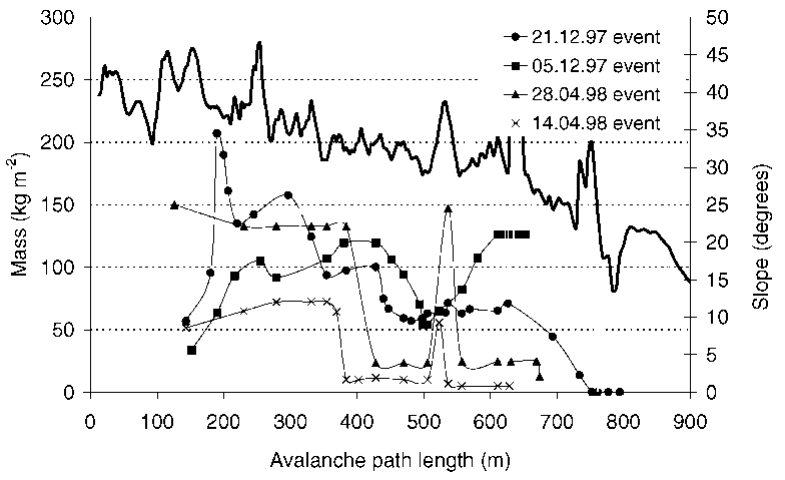

Fig. 6. Comparison between different erosion rates.

information has been interpolated using a third-order polynomial. The derivative of the polynomial has supplied the avalanche frontal speed at each point of its trajectory.

Figure 5 shows the speed in relation to the slope of the track, as well as the maximum runout distances reached by each avalanche. For a long segment of track between the release point and the first surveyed point, there is no information related to the dynamics of the phenomenon. Generally the investigated avalanches start to decelerate where the slope angle is $<30^{\circ}$. Different runout distances are reached for the examined events. The maximum runout distance was reached by the 21 December event which also attained the maximum speed and mass values. The other events reached more or less the same distance, stopping immediately after a sudden change of slope. It is important to observe the behaviour of the 28 April avalanche (wet avalanche), which is characterized by a very low value of the frontal speed but reached the same runout distance as avalanches with higher speeds.

\section{EROSION AND DEPOSITION ANALYSIS}

Comparison of the mass-balance analyses for the examined events shows a rather consistent behaviour. Considering the erosion for unit surface $\left(\mathrm{kg} \mathrm{m}^{-2}\right)$, it is possible to observe that the avalanche collects snow all along its trajectory. In the first part of the track, where the acceleration is positive, the part of snow cover eroded per unit surface reaches the maximum value. High values of erosion are also reached following a sudden increase of slope (see Fig. 6). The analysis of the snow cover after the event shows the tendency of the avalanche to erode the same layers for long sections of the track. It was also observed that the avalanche eroded low-density snow all the

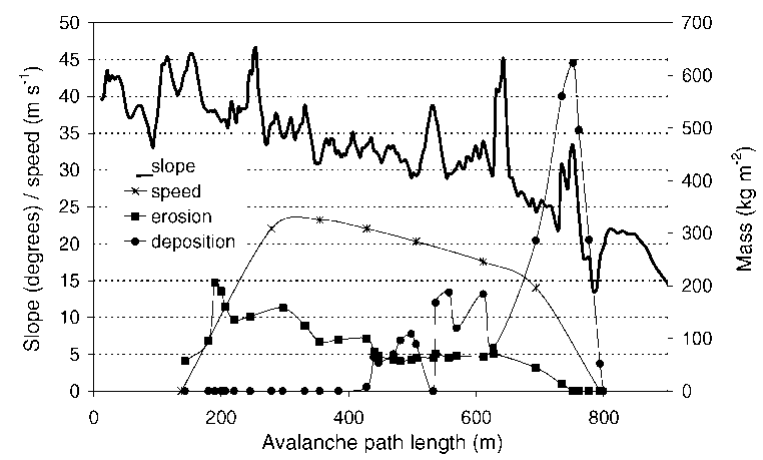

Fig. 7. Event of 21 December 1997: comparison between erosion and deposition $\left(\mathrm{kg} \mathrm{m}^{-2}\right)$, speed and slope.

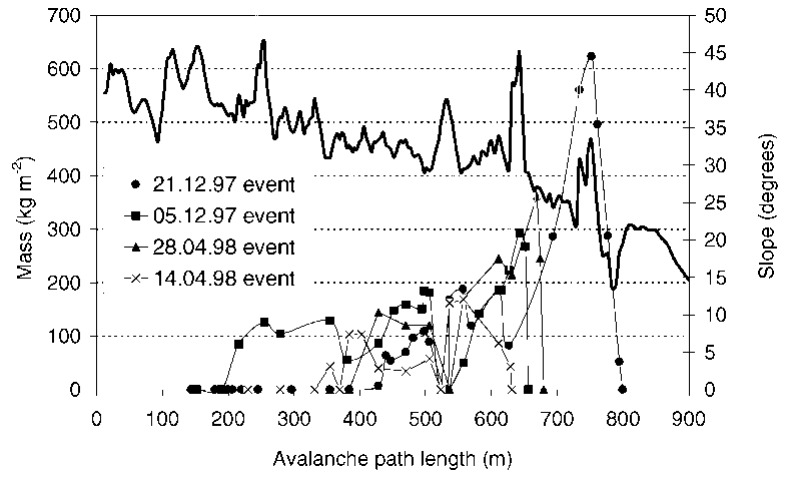

Fig. 8. Comparison between different deposition distributions.

way down to the ground along the entire avalanche path. When the acceleration becomes negative and the frontal speed begins to decrease, the avalanche starts to deposit (e.g. the 21 December 1997 event; Fig. 7).

An exception is the 5 December 1997 event, when deposition started immediately after the release zone, probably because of the high friction value between the avalanche and the ground not yet affected by the passage of previous events (see Fig. 8). In this case several accelerations and decelerations of the avalanche were observed, which produced erosions and depositions uniformly distributed throughout the trajectory. Because of this behaviour the avalanche was not able to reach high speed and mass value but the continued erosion kept the avalanche mass positive, allowing a considerable runout distance to be reached.

\section{SUMMARY OF RESULTS}

Four events have been studied (see Table 1), two of small dimensions (5 December and 14 April) and two medium (21 December and 28 April). We have observed that many factors could influence the dynamics of the avalanche. For small avalanches the speed and the mass reached by the avalanche are strongly related to the topographic factors and to the kind of snow. The two events started with almost the same mass, but because of the different kinds of substratum the 14 April avalanche reached a mass double that of the 5 December event. In spite of the different mass, the speed was almost the same, probably because of differences in the water content of the snow. The runout distance was influenced more by topographic factors than by dynamical parameters. The small avalanches reached the same runout distance because of the sudden change of slope.

The medium avalanches were less influenced by the topographic factors. In this case the big difference was the water content of the snow. The wet avalanche (28 April) did not reach a high speed, but its mass allowed a longer runout distance of the small events.

When the external parameters, such as substratum, characteristics of the slope, water content of the snow and quantity of the snow that the avalanche can erode along the path, favour avalanche development, the avalanche can strongly increase its mass. For example, the avalanche of 21 December grew to 7.2 times its initial mass.

An interesting observation concerns the increase of density of the deposited snow in comparison with the undisturbed snow cover. The ratio is $2-3$. Only for wet snow is the ratio equal to 1 . 
Table 1. Summary of the mass-balance results

\begin{tabular}{|c|c|c|c|c|c|c|c|c|c|}
\hline Event & Typology & $\begin{array}{c}\text { Release mass } \\
(\mathrm{Rm}) \\
\mathrm{kg}\end{array}$ & $\begin{array}{l}\text { Maximum } \\
\text { mass }(\mathrm{Mm}) \\
\mathrm{kg}\end{array}$ & $R m / M m$ & Average speed & Runout & $\begin{array}{l}\text { Release density } \\
\qquad(R d)\end{array}$ & $\begin{array}{l}\text { Deposit density } \\
(D d)\end{array}$ & $D d / R d$ \\
\hline 5 December 1997 & Dry & 33700 & 61600 & 1.8 & 11.0 & 547 & 135 & 280 & 2.1 \\
\hline 21 December 1997 & Dry & 84400 & 505850 & 7.2 & 17.9 & 680 & 140 & $270 \div 430$ & $1.9 \div 3.1$ \\
\hline 14 April 1998 & Moist & 30900 & 126800 & 4.1 & 12.3 & 530 & 115 & $290 \div 345$ & $2.5 \div 3$ \\
\hline 28 April 1998 & Wet & 90000 & 296700 & 3.3 & 7.6 & 580 & 500 & $500 \div 560$ & $1 \div 1.1$ \\
\hline
\end{tabular}

\section{GONGLUSIONS AND DEVELOPMENTS}

The avalanche mass is not constant along the track. Analyzing the most important event of the season (21 December 1997) we observe that the mass increases to $720 \%$ with respect to the initial mass, suggesting that the quantity of snow that the avalanche can potentially erode along the path is more important than the release mass. The mass increase is more important for avalanches having a small release area and a long flowing zone.

The slope angle is the most important factor in the erosion and deposition processes. The erosion reaches its maximum value on slopes of $>30^{\circ}$. The deposition starts when the slope angle drops below about $30^{\circ}$ and the avalanche acceleration becomes negative.

Existing theories of avalanche dynamics and the simulation models do not consider the effect of the entrainment and deposition along the path, and the mass of the simulated avalanche corresponds to the initial mass. This work aims to collect information that will be used to implement and verify numerical models to simulate avalanche events having variable mass. The development of this work consists in examining closely the erosion and deposition processes in order to determine the physical behaviour of this phenomenon. New experiments and field measurements have already been planned. The goal of these experiments is to collect more detailed measurements related to a wide variety of avalanches.

\section{ACKNOWLEDGEMENTS}

We thank A. Luchetta, W. Ammann and P. Bartelt for supporting this work, D. Issler for the fundamental discussions, all the surveyors of the Avalanche Centre of Arabba and the Alpine Guide for essential help with data collection in the field.

\section{REFERENCES}

Barbolini, M. 1996. Sulla simulazione delle valanghe di neve densa. (Tesi di laurea, Politecnico di Milano.)

Dent, J. D., K. J. Burrell, D. S. Schmidt, M.Y. Louge, E. E. Adams and T. G. Jazbutis. 1998. Density, velocity and friction measurements in a drysnow avalanche. Ann. Glaciol., 26, 247-252.

Eglit, M. 1983. Some mathematical models of snow avalanches. In Shahinpoor, M., ed. Advances in the mechanics and the flow of granular materials. Vol. 2. Houston, TX, Gulf Publ. Co. Clausthal-Zellerfeld, 577-588. (Trans Tech Publ.)

Grigorian, S. S. and A.V. Ostoumov. In press. Mathematical modeling of snow avalanches movement. In Proceedings of the Symposium: 60 Kears Snow and Avalanche Research at Davos. Davos-Dorf, Eidgenössisches Institut für Schnee- und Lawinenforschung.

Harbitz, C. B. 1998. A survey of computational models for snow avalanche motion. In Harbitz, C. B., ed. SAME snow avalanche modelling, mapping, and warning in Europe. Oslo, Norwegian Geotechnical Institute, 23-71. (NGI Report 581220-1.)

Harbitz, C. B., D. Issler and C. J. Keylock. 1998. Conclusions from a recent survey of avalanche computational models. In Hestnes, E., ed. 25 Tears of Snow Avalanche Research, Voss 12-16 May 1998. Proceedings. Oslo, Norwegian Geotechnical Institute, 128-139. (NGI Publication 203.)

Issler, D., ed. 1999. European avalanche test sites. Overview and analysis in view of coordinated experiments. Eidg. Inst. Schnee- und Lawinenforsch. Mitt. 59.

Kawada, K., K. Nishimura and N. Maeno. 1989. Experimental studies on a powder-snow avalanche. Ann. Glaciol., 13, 129-134.

Kotlyakov, V. M., B. N. Rzhevskiy and V. A. Samoylov. 1977. The dynamics of avalanching in the Khibins. F. Glaciol., 19(81), 431-439.

Marco, O. 1995. Instrumentation d'un site avalancheux. Grenoble, Centre National du Machinisme Agricole du Génie Rural des Eaux et des Forêts (CEMAGREF). (ÉTUDES Équipements pour l'Eau et l'Environnement 16.)

McClung, D. M. and P. A. Schaerer. 1985. Characteristics of flowing snow and avalanche impact pressures. Ann. Glaciol., 6, 9-14.

Nishimura, K., N. Maeno, K. Kawada and K. Izumi. 1993. Structures of snow cloud in dry-snow avalanches. Ann. Glaciol., 18, 173-178.

Sommavilla, F. and B. Sovilla. 1998. The avalanche monitoring system of Mount Pizzac. In Hestnes, E., ed. 25 Years of Snow Avalanche Research, Voss 12-16 May 1998. Proceedings. Oslo, Norwegian Geotechnical Institute, 268-273. (NGI Publication 203.)

Sommavilla, F., B. Sovilla and A. Tomaselli. 1997. Il sistema di monitoraggio per l'acquisizione dei parametri dinamici delle valanghe. Neve e Valanghe 31, 6-17. 